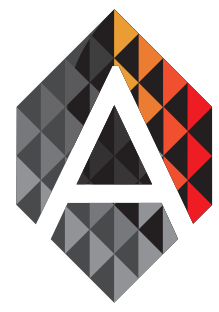

ADCAIJ: Advances in Distributed Computing and Artificial Intelligence Journal Regular Issue, Vol. 8 N. 1 (2019), 49-54

eISSN: $2255-2863$

DOI: http://dx.doi.org/10.14201/ADCAIJ2019814954

\title{
Multi-agent system for selecting images based on the gender and age
}

\author{
Álvaro Martín, David Trejo, Alejandro Yagüe, \\ and José Sánchez
}

alvaroams@usal.es,nanotrejo@usal.es, ayague@usal.es, josesanchez97@usal.es University of Salamanca

\begin{tabular}{ll} 
KEYWORD & ABSTRACT \\
\hline $\begin{array}{l}\text { Multi-Agent; } \\
\text { Facial }\end{array}$ & $\begin{array}{l}\text { This paper presents a multi-agent system that is able to search people on a database } \\
\text { of images recognizing patterns of facial features on each person, based on the main } \\
\text { Recognition; }\end{array}$ \\
$\begin{array}{l}\text { Artificial Vision; } \\
\text { Biometrics }\end{array}$ & $\begin{array}{l}\text { system can do the work faster applying Fisherfaces algorithm for the face recognition } \\
\text { and classification. This technology can be used for several purposes like specific ads in } \\
\text { each user group to suit better their interests or search for the age and gender of people } \\
\text { that usually go to different places like malls or shops. }\end{array}$ \\
\hline
\end{tabular}

\section{Introduction}

Facial recognition is a biometric solution that uses a series of algorithms to verify, recognize the identity or describe the main features of a person based on their physiological characteristics. This has led to the development of different techniques that extract information from the image (Mehra and Charaya, 2016; Kas et al., 2018; López and González, 2016) These techniques are based on analyzing the physical features of the face, aligning those that are in an unusual position, extracting the characteristics of the image and recognizing the data in order to classify them by sex and age. In this article we propose a searching system to solve one of the actuals objectives of the facial recognition that is to identify the gender and age of a person through an image with the best accuracy possible and the minor response time possible (Lopez et al., 2017). There are other applications such as secure electronic voting (Alim et al., 2017), smart glasses (Xu et al., 2018), robotics (Debdeep Banerjee and Kevin Yu, 2018), user authentication (Lin et al.,2016), recognition of emotions (Yamaguchi et al, 2016). There are also other interesting biometric solutions like ear recognition (Galdámez and González, 2013) retinal information (Chamoso et al., 2014).

In this work, a multi-agent system is used, composed of intelligent entities agents that are encapsulated to coordinate, communicate, interact and cooperate with each other to solve problems that would be more difficult to solve by a single agent. They are a part of the architecture that carry out several tasks such as answering the user to the parameters of the search, obtaining images, recognizing the physical features of the face and obtain an approximation to his gender and age, mix the images and classify that features to subsequently obtain an answer to the search.

The proposed architecture is composed of 4 reactive agents (Brooks, 1986) and a mobile agent that travel around the net to obtain the images necessary for the system. In this architecture each agent has a specific

Álvaro Martín, David Trejo, Alejandro Yagüe, and José Sánchez

Multi-agent system for selecting images based on the gender and age
ADCAIJ: Advances in Distributed Computing and Artificial Intelligence Journal Regular Issue, Vol. 8 N. 1 (2019), 49-54 eISSN: 2255-2863 - http://adcaij.usal.es Ediciones Universidad de Salamanca - CC BY NC DC 
behavior based on its hierarchy on the system and react to the user input or the call of another agent. These agents are created to share information and knowledge in an easy to understand way.

This paper is organized as follows: Section 2 describes the proposed architecture, Section 3 presents the case study in which the platform is applied and the results of this implementation, and lastly, conclusions are discussed in Section 4.

\section{System Overview}

The proposed system is a reactive multi-agent architecture, developed for searching a set of characteristics on images. All the required tasks are done by separated agents, from interacting with the user who starts the search to obtain the images, classify them and show the results. Different types of agents in multi-agent system for selecting images based on the gender and age are 'Controller agent', 'Image holder', 'age agent', 'genre agent' and 'recognition agent' composing a hierarchy architecture. These agents are briefly described below.

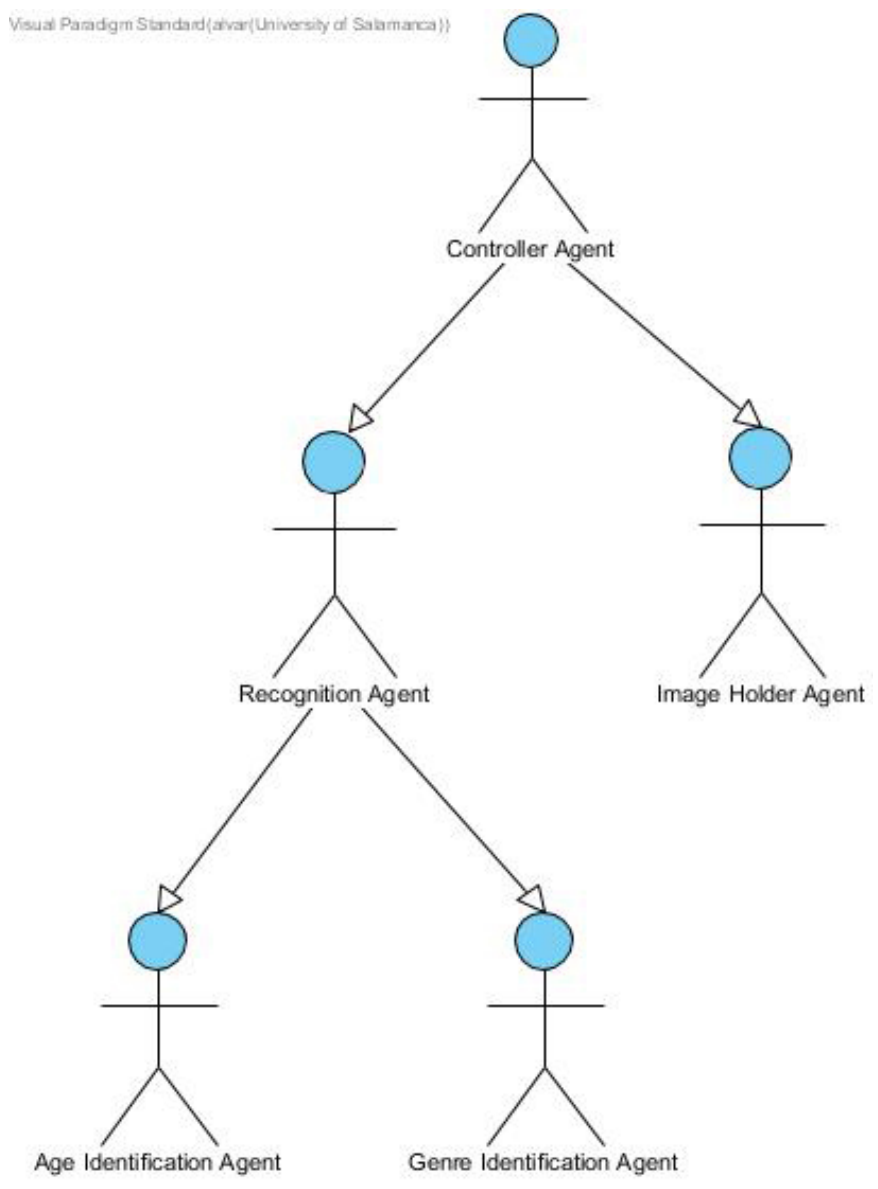

Figure 1: Architecture of the agents

- Controller Agent: Reactive agent that is responsible to manage the coordination between the user and all the other agents. This agent reacts to the interaction with the user who wants to search for images and takes the responsibility of activation and synchronization of the other agents. When the work is done this agent show the results to the user.

Alvaro Martín, David Trejo, Alejandro Yagüe, and José Sánchez

Multi-agent system for selecting images based on the gender and age
A
ADCAIJ: Advances in Distributed Computing and Artificial Intelligence Journal Regular Issue, Vol. 8 N. 1 (2019), 49-54 eISSN: 2255-2863 - http://adcaij.usal.es Ediciones Universidad de Salamanca - CC BY NC DC 
- Age Agent and Genre Agent: Two reactive agents that recognize the age and the gender of a person in a photo and communicate to the other agents to prepare a reply to the answer of the user using a series of algorithms.

- Recognition Agent: Reactive agent that apply filters to the image and coordinate the results obtained of the age and genre agent and reply and store the answers to communicate to the users and to have a historical of queries and make the search faster.

- Image holder Agent: Goal-Based agent in charge of obtaining images, store them and providing to the other agents to accomplish the objective of classify them.

- The communication between the different agents is developed according to the FIPA ACL, the Agent Communication language developed by FIPA, allowing to make messages with different types of semantics and information, using different performatives in each kind of message.

The facial recognition algorithm used is the one with best results in a comparison (Briones et al. 2017). This algorithm recognizes the face based on the main features and other things like light, combined with Discriminant Lineal Fisher reduce the dimensionality and applying the bilateral filter to make the results more accurate and preprocessing the image to align the center the face in the picture and deleting unnecessary information to make the process faster (Belhumeur et al., 1997).

The images are obtained from the database, uploaded in the Image holder Agent and share for the other agents. These agents developed search for features of the face and applying a series of algorithm we calculate an answer. We can observe in the Figure 2 the communications between the agents in order to complete the job classification based on the genre and age. The system is developed using JADE framework, a open source available system with GNU license developed in java. JADE is compliant with the FIPA specifications. The FERET database combined with photographs of volunteers to create a database big enough to work with.

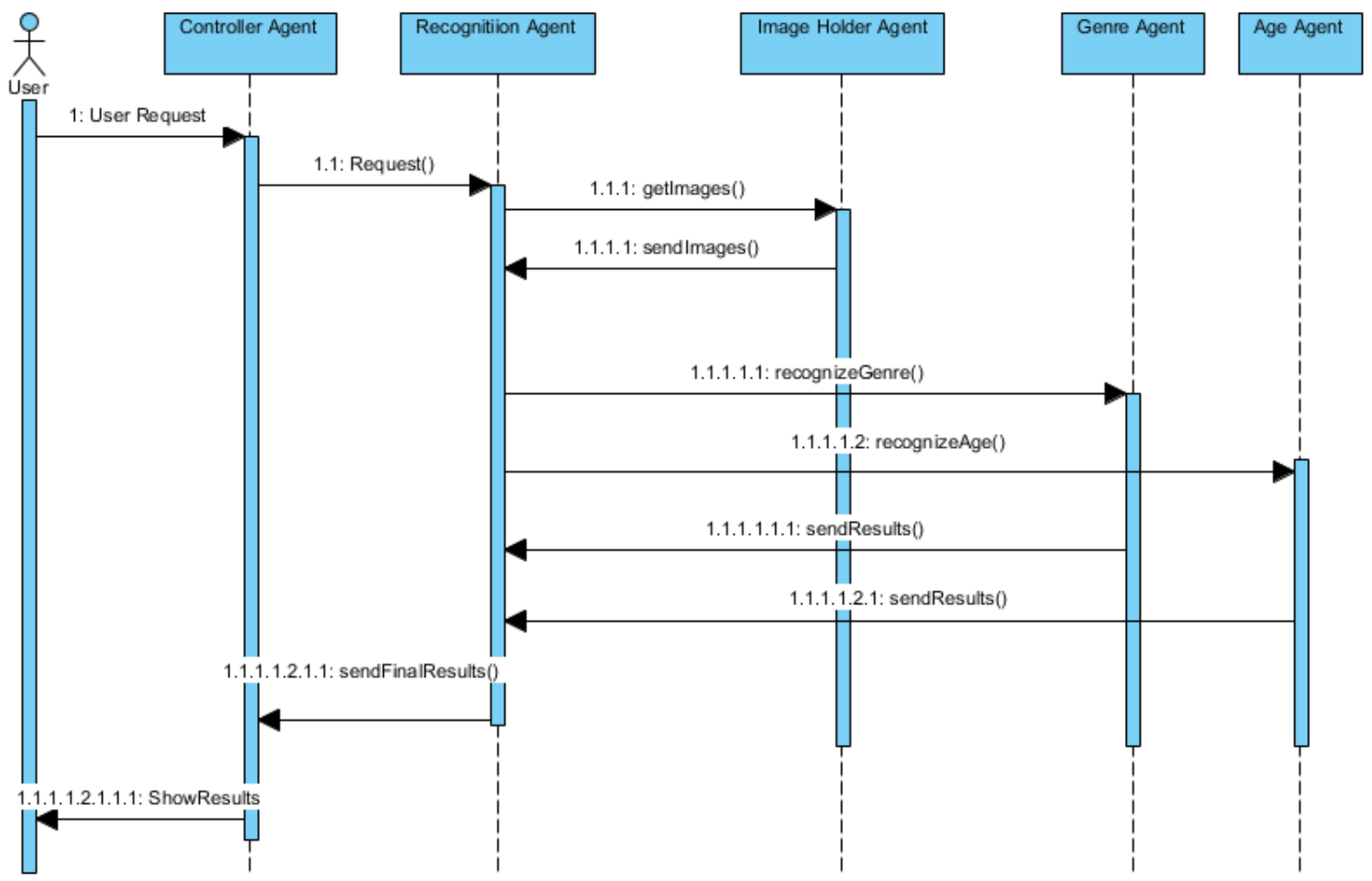

Figure 2: Communication between agents

Álvaro Martín, David Trejo, Alejandro Yagüe, and José Sánchez

Multi-agent system for selecting images based on the gender and age
ADCAIJ: Advances in Distributed Computing and Artificial Intelligence Journal Regular Issue, Vol. 8 N. 1 (2019), 49-54 eISSN: 2255-2863 - http://adcaij.usal.es Ediciones Universidad de Salamanca - CC BY NC DC 
As shown on Fig. 2 all the data is controlled by the "controller agent" that is necessary for the correct behavior of the whole system to recognize the age and genre of human pictures. In this "controller agent" is collected the data typed in by the user and is send to the other agents for doing the corresponding tasks. Recognition agent demand the photos to image holder agent and then send it to Genre and Age Agents to recognize and then send back to them. When the work is done controller agent show the information to the user and ask for more data to search.

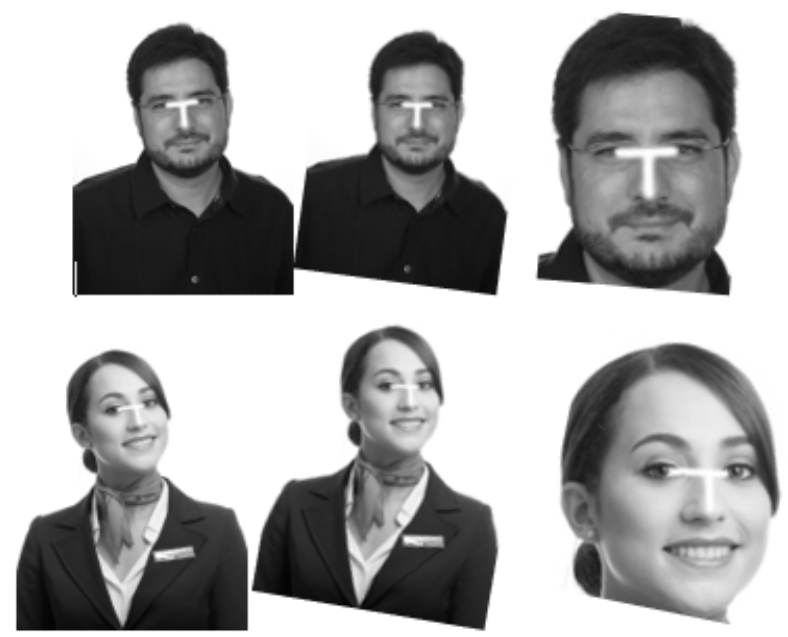

Figure 3: Use of filters and preprocessing

\section{Results and Conclusions}

The obtained data show the results of user Fisherfaces algorithm with the preprocessing and filters used. The success rate is not bad, but more work had to be done in this area in order to improve the results and the time necessary to complete the search. These three completed iterations are done with a database of 120 pictures to avoid penalizing the times of the search with a larger number of photographs. The system has proven to accomplish the objective of returning images with the required features.

\begin{tabular}{ccccc}
\hline & First Search & Second Search & Third Search & Fourth Search \\
\hline Fisherfaces & $64.98 \%$ & $59.23 \%$ & $67.35 \%$ & $62.68 \%$ \\
\hline Search (s) & 22.94 & 18.25 & 19.02 & 19.84 \\
\hline
\end{tabular}

Figure 4: percentage of success and times of response

Álvaro Martín, David Trejo, Alejandro Yagüe, and José Sánchez

Multi-agent system for selecting images based on the gender and age
ADCAIJ: Advances in Distributed Computing and Artificial Intelligence Journal Regular Issue, Vol. 8 N. 1 (2019), 49-54 eISSN: 2255-2863 - http://adcaij.usal.es Ediciones Universidad de Salamanca - CC BY NC DC 
Please type the data you want to find:

Genre (M/F): $f$

Age (MIN): 20

Age $(M A X): 40$

Results:

\begin{tabular}{|l|l} 
IMA_02 & $\mathrm{F}$ \\
IMA_03 & $\mathrm{F}$ \\
IMA_04 & $\mathrm{F}$ \\
IMA_05 & $\mathrm{F}$ \\
IMA_08 & $\mathrm{F}$ \\
IMA_08 & $\mathrm{F}$ \\
IMA_12 & $\mathrm{F}$ \\
IMA_15 & $\mathrm{F}$ \\
IMA_16 & $\mathrm{F}$ \\
IMA_19 & $\mathrm{F}$ \\
IMA_20 & $\mathrm{F}$ \\
IMA_21 & $\mathrm{F}$ \\
IMA_23 & $\mathrm{F}$ \\
IMA_24 & $\mathrm{F}$ \\
IMA_26 & $\mathrm{F}$ \\
IMA_29 & $\mathrm{F}$ \\
IMA_31 & $\mathrm{F}$ \\
IMA_39 & $\mathrm{F}$ \\
IMA_41 & $\mathrm{F}$ \\
IMA_48 & $\mathrm{F}$
\end{tabular}

Please type the data you want to find:

Genre (M/F): m

Age (MIN): 20

Age $(\operatorname{MAX}): 30$

Results:

\begin{tabular}{|l|l} 
IMA_01 & M \\
IMA_06 & $M$ \\
IMA_17 & $M$ \\
IMA_27 & M \\
IMA_28 & M \\
IMA_32 & $M$ \\
IMA_36 & M \\
IMA_47 & M \\
IMA_47 & M \\
IMA_52 & IMA
\end{tabular}

Please type the data you want to find:

Genre (M/F): $f$

Age (MIN): 30

Age $(M A X): 60$

Results:

\begin{tabular}{|l|l|l|} 
IMA_02 & $\mathrm{F}$ & 33 \\
IMA_03 & $\mathrm{F}$ & 40 \\
IMA_05 & $\mathrm{F}$ & 31 \\
IMA_12 & $\mathrm{F}$ & 31 \\
IMA_19 & $\mathrm{F}$ & 37 \\
IMA_22 & $\mathrm{F}$ & 59 \\
IMA_23 & $\mathrm{F}$ & 34 \\
IMA_24 & $\mathrm{F}$ & 31 \\
IMA_25 & $\mathrm{F}$ & 44 \\
IMA_29 & $\mathrm{F}$ & 30 \\
IMA_31 & $\mathrm{F}$ & 38 \\
IMA_41 & $\mathrm{F}$ & 32 \\
IMA_42 & $\mathrm{F}$ & 60 \\
IMA_46 & $\mathrm{F}$ & 50
\end{tabular}

Please type the data you want to find:

Genre (M/F): m

Age (MIN): 50

Age $($ MAX) : 75

\section{Results:}

\begin{tabular}{|l|l} 
IMA_13 & $M$ \\
IMA_14 & $M$ \\
IMA_34 & $M$ \\
IMA_38 & $M$ \\
IMA_43 & $M$ \\
IMA_45 & $M$ \\
IMA_51 & |
\end{tabular}

Figures 5: Results of some searches

This work consists on apply a multi-agent system designed for the search of human images with a series of requirements based on a classification of gender and age, using different filters for an improvement of the image quality, together with the Fisherfaces algorithm, which will obtain the necessary data for a correct classification of the images imported by the Feret database. The system allows to easily analyze these images thanks to the communication between the different agents that each of them have a predetermined function to achieve a common objective.

Future works in this area is our objective, to develop a system that can classify people in real time video or in a bigger number of pictures with more complex algorithms and filters and make more efficient the multi-agent system to decrease the time and the power necessary for the system to finish the task.

Álvaro Martín, David Trejo, Alejandro Yagüe, and José Sánchez

Multi-agent system for selecting images based on the gender and age
ADCAIJ: Advances in Distributed Computing and Artificial Intelligence Journal Regular Issue, Vol. 8 N. 1 (2019), 49-54 eISSN: 2255-2863 - http://adcaij.usal.es Ediciones Universidad de Salamanca - CC BY NC DC 


\section{References}

Belhumeur, P.N., Hespanha, J.P., and Kriegman, D.J., 1997. Eigenfaces vs. fisherfaces: Recognition using class specific linear projection. IEEE Trans. Pattern Anal. Mach. Intell. 19 (7), 711-720.

Brooks, R.A., 1986. A Roboust Layered Control System for a Mobile Robot. IEEE Journal of Robotics and Automation RA-2, 14-23.

Chamoso, Pablo, Pérez-Ramos, Henar, and García-García, Ángel, 2014. Altair: Supervised Methodology to Obtain Retinal Vessels Caliber. ADCAIJ: Advances in Distributed Computing and Artificial Intelligence Journal, Salamanca, v. 3, n. 4, p. 48-57, dec. ISSN 2255-2863.

Corchado, J. M., Bajo, J., De Paz, Y., and Tapia, D. I., 2008. Intelligent environment for monitoring Alzheimer patients, agent technology for health care. Decision Support Systems, 44(2):382-396.

Corchado, J. M., Pavón, J., Corchado, E. S., and Castillo, L. F., 2004. Development of CBR-BDI agents: a tourist guide application. In Advances in case-based reasoning, pp. 547-559. Springer.

Debdeep Banerjee, and Yu Kevin, 2018. Robotic Arm-Based Face Recognition Software Test Automation.

Frikha, T., Siala, Y., Louati, M., and Abid, M., 2016. Use of ridgelets, curvelets application for face recognition: Case study: smart identity card. Advanced Technologies for Signal and Image Processing (ATSIP), 2nd International Conference on. IEEE.

Galdámez, Pedro L., and González Arrieta, Angélica, September 2013. Ear Biometrics: A Small Look at the Process of Ear Recognition. International Joint Conference SOCO'13-CISIS'13-ICEUTE'13. Salamanca, Spain, September 11th-13th, Proceedings. Advances i.

Gil, A.B., Rodríguez-González, S., and Corchado, J.M., 2015. Cloud Computing and Multi Agent System to improve Learning Object Paradigm. Interaction Design and Architecture (s) (23), 38-49.

Kas, Mohamed \& Merabet, Youssef \& Ruichek, Yassine, \& Messoussi, Rochdi, 2018. Mixed Neighborhood Topology Cross Decoded Patterns For Image-Based Face Recognition. Expert Systems with Applications. 114. 10.1016/j.eswa.2018.07.035.

López Sánchez, Daniel, and González Arrieta, Angélica, 2016. Preliminary results on nonparametric facial occlusion detection. ADCAIJ: Advances in Distributed Computing and Artificial Intelligence Journal, Salamanca, v. 5, n. 1, pp. 51-61, jan. ISSN 2255-2863.

López-Sánchez, Daniel, Corchado, Juan M., and González Arrieta, Angélica, 2017. A CBR system for e cient face recognition under partial occlusion Case-Based Reasoning Research and Development: 25th International Conference, ICCBR 2017, Trondheim, Norway, June 26-28, 2017, Proceedings. Lecture Notes in Computer Science. Volumen 10339, pp. 170-184.

Lu, C.-Y., Min, H., Gui, J., Zhu, L., and Lei, Y.-K., 2013. Face recognition via weighted sparse representation. J. Visual Commun. Image Represent. 24 (2), 111-116.

Robertson, D.J., and Burton, A.M., 2016. Unfamiliar face recognition: Security, surveillance and smartphones. J. Homeland Defense Secur.Inf. Anal. Center 14-21.

Schmidhuber, J., 2014. The Swiss AI Lab IDSIA, Istituto Dalle Molle di Studi sull'Intelligenza Artificiale, University of Lugano \& SUPSI, Galleria 2, 6928 Manno-Lugano, Switzerland.

Sirovich L., and Kirby M., 1987. Low-dimensional procedure for the characterization of human faces. Journal of the Optical Society of America A. 4 (3): 519-524.

Xu Weitao, Shen Yiran, Bergmann Neil, and Hu Wen, 2018. Sensor-Assisted Multi-View Face Recognition System on Smart Glass. IEEE Transactions on Mobile Computing (Volume: 17, Issue: 1, Jan. 1 2018): 197210 (https://ieeexplore.ieee.org/abstract/document/7922583).

Yamaguchi, Naoya; Navarro Cáceres, María; de la Prieta Pintado, Fernando; Matsui, Kenji (2016) Facial Expression Recognition System for User Preference Extraction. Distributed Computing and Artificial Intelligence, 13th International Conference. Advances in Intelligent Systems and Computing. Volume 474, pp. 453-461.

Alvaro Martín, David Trejo, Alejandro Yagüe, and José Sánchez

Multi-agent system for selecting images based on the gender and age
ADCAIJ: Advances in Distributed Computing and Artificial Intelligence Journal Regular Issue, Vol. 8 N. 1 (2019), 49-54 eISSN: 2255-2863 - http://adcaij.usal.es Ediciones Universidad de Salamanca - CC BY NC DC 